\title{
A Dynamical Study of Risk Factors in Intracerebral Hemorrhage using Multivariate Approach
}

\author{
Afaq Ahmed Siddiqui ${ }^{1, *}$, Junaid S. Siddiqui ${ }^{2}$, Mohammad Wasay ${ }^{3}$, S. Iqbal Azam ${ }^{4}$ and \\ Asif Ahmed ${ }^{5}$
}

${ }^{1}$ Department of Pharmaceutical Chemistry, Faculty of Pharmacy, University of Karachi, Karachi, Pakistan

${ }^{2}$ Department of Statistics, University of Karachi, Karachi, Pakistan

${ }^{3}$ Neurology Section, Department of Medicine, The Aga Khan University, Karachi, Pakistan

${ }^{4}$ Community Health Sciences Department, Aga Khan University, Karachi, Pakistan

${ }^{5}$ Baqai Medical University, Karachi, Pakistan

\begin{abstract}
The purpose of this study is to investigate the effects of clinical covariates to the outcome of Intracerebral Hemorrhage (ICH) patients in terms of best fitted and excellent discriminate model of binary response variable.

Clinical data of 985 patients with ICH have collected using the International classification of diseases, Ninth revision codes. The diagnosis of ICH was confirmed by neuro-imaging in all patients.

Univariate analysis revealed that out of 88 covariates 46 were found to be significant $(p<0.05)$. The multivariable analysis using multiple logistic regressions, exhibited a significant negative relationship between $\mathrm{ICH}$ and hypertension. The improvement among $\mathrm{ICH}$ patients having hypertension was 0.5 ( $p=0.001$, ARR=0.5, 95\% C.I. 0.3 - 0.8). The improvement among ICH patients using antihypertensive medicine was $1.3(p=0.016$, ARR=1.3, 95\% C.I. $1.1-1.5)$. Thus present study showed that $\mathrm{ICH}$ has strong relationship with use of antihypertensive medicine. The improvement of patients who were using antihypertensive medicine at the time of discharge was 3.0 times $(p<0.0001, A R R=3.0,95 \%$ C.I. 2.7 - 3.2) as compared to those who did not use antihypertensive medicine. The change in ARR from 1.3 to 3.0 times shows that the use of antihypertensive medicine and ICH outcome variable are positively associated. The change in ARR of hypertensive range of SBP also indicates that the blood pressure range and ICH outcome variable are negatively associated. The neurological symptomatology, slurred speech and double vision are important factors of proposed statistical models. Moreover, a clear decrease was found in mental status from normal to coma in applicable model.

Surgery is an important part of recovery, and estimated that the improvement among the ICH patients, who were treated with surgery, was 1.4 times with significant $p$-value in best fitted models. The complication of pneumonia during treatment of $\mathrm{ICH}$ subjects has highly significant negative association with outcome variable.

Present Model has 0.892 area under the curve with sensitivity (0.852), specificity (0.793) and p-value $(0.204)$. This indicates that the model gives the impression to fit quite well for predictive performance of the $\mathrm{ICH}$ outcome variable and the model is excellent model.
\end{abstract}

Keywords: Intracerebral Hemorrhage, clinical covariates, multivariable analysis, logistic regression, discriminate model, sensitivity and specificity.

\section{INTRODUCTION}

The brain is an "end organ" and gets its blood supply through network of blood vessels in the body. These vessels are the least prepared to handle the chronic increase in blood pressure. At the same time, they are responsible for carrying a larger amount of blood to a very vital area, at relatively high pressures. Thus, over the years, they can develop microscopic outpouchings called Charcot Aneurysms (place where a blood vessel has become swollen). Rupture of blood vessel causes Intracerebral Hemorrhagic stroke. Intracerebral Hemorrhage (ICH) thus refers to bleeding

*Address correspondence to this author at the Department of Pharmaceutical Chemistry, Faculty of Pharmacy, University of Karachi, Karachi, Pakistan; E-mails: aasiddiqui@uok.edu.pk, siddiquiaapak@yahoo.com into parenchyma of the brain that may extend into the ventricles or rarely into subarachnoid spaces.

The global rate of occurrence of Intracerebral Hemorrhage (ICH) is $10-20 / 100,000$ populations. It is noted that male suffer more than female. Moreover people aged more than 55 years have been noted to be at the maximum risk $[1,2]$. Intracerebral Hemorrhage is not only a major issue in third world countries but it is reported to be a major issue also in the USA and UK. Regrettably it is estimated that mortality of $\mathrm{ICH}$ is expected to become two fold by the year 2050. The unidentified reason is increase in aging population as well as changing in racial demographics [3-5].

Stroke is the third leading cause of death and the first leading cause of disability $[2,5]$. Morbidity is more 
severe and mortality rates are higher for hemorrhagic stroke than for ischemic stroke. Spontaneous Intracerebral Hemorrhage accounts for 10 to $15 \%$ of all strokes [6]. The 30-day mortality rate for hemorrhagic stroke is $40-80 \%$. Approximately $50 \%$ of all deaths occur within the first 48 hours. The survival rate in Intracerebral Hemorrhage is only $38 \%$ in one year [4, 5, 7].

\section{PATIENTS AND METHODS}

\section{Patients}

Retrospective clinical data of 985 patients with Intracerebral Hemorrhage (ICH) over an 18 years period (1988-2005), were collected from one of the largest tertiary care hospital situated in Karachi. Patients were identified through medical records at the hospital using the International classification of diseases, Ninth revision coding system. Diagnostic codes (434 for stroke and 431 for ICH) were used to identify patients. The diagnosis of $\mathrm{ICH}$ was confirmed by neuro-imaging in all patients.

\section{Statistical Approaches}

The clinical data was processed by coding, editing, tabulating, recoding, re-tabulating and finally analyzed using different statistical tools. In analysis, we first assessed the univariate association between the response variable and a covariate using Chi- square test and logistic regression analysis. All variables with $p$-value less than 0.25 on univariate analysis were then included in multivariable analysis. A stepwise procedure was used to select the variable with a value of $p<0.25$ as the inclusion criteria for best fitted multivariable model. A number of models containing all possible combinations of variables were significant according to defined criteria, comparing the models through the likelihood ratio test.

The association between the various causal variables associated with each other biologically was also assessed. These variables, having statistically significant $p$-values, were possible confounders and their odd ratios changed significantly in multivariable analysis but were not strongly associated with each other because of $p$-value $>0.05$. After developing main effect model, a relationship was tried to seek out with the interactions which were biologically meaningful but none of them were found to be significant.

In the present study, Hosmer-Lemeshow test statistics was used to assess the goodness of fit for logistic regression model. It is frequently used in risk prediction models; particularly during the assessment of human disease models [8-14].

Finally, the discrimination of the predictive models is determined by measuring the area under the receiver operating characteristic (ROC) curve and obtains the cutoff which can best predict the outcome. In current study sensitivity and specificity analysis is based on binary classification of actual outcome and predictive probabilities of outcome of models. The SPSS software (ver. 12) is used to perform all the statistical analysis.

\section{ANALYSIS AND RESULT}

In univariate analysis Pearson Chi-square and likelihood ratio test were performed for $p$-value and test of association , and logistic regression was used for RR (relative risk) with 95\% confidence interval. It was revealed that out of 88 covariates 46 were significant according to $p$-value $<0.05$ (Table 1).

After preliminary analysis, any variable whose pvalue was found to be less than 0.25 on univariate analysis or otherwise thought to be biologically meaningful [10, 15-17] were entered into multivariable analysis using forward stepwise logistic regression, likelihood ratio test were used for variable selection. We only had two continuous variables which were age and length of stay. After analyzing the associations of the two continuous variables with outcome variable, it was found that both are statistically insignificant.

We tried to investigate the interactions which are biologically meaningful but none were found to be significant according to the $p$-value criteria (Table 2).

After the process of including, deleting, refitting with different combinations of all important (statistically and lor clinically) variables and their interactions (biologically), different models were obtained using multiple logistic regression. One best fitted multiple logistic regressions model is as follows:

$g(x): 0.9-1.17$ (htn) -1.3 (coag) +0.58 (mahtn) 0.57 (slusp) -1.88 (dbvis) $+0.13(\mathrm{mssl})-0.67$ (msco2) 0.13 (mspr3) -0.92 (msur4) -1.16 (msco5) -1.1 (lsbp 1$)+$ 0.04 (Isbp2)-0.9(Isbp3)-1.19(Isbp4)+ 0.12(mtnor) + 2.06 (mtrmp) $\quad-0.06$ (lorbg) $\quad+0.68$ (loput)-0.3 (lopon) +1.2 (locer) +0.46 (lofrl) +0.3 (lopal) -0.3 (memidsh) + 0.43 (meintb) -0.4 (mehydr) -0.9 (menorm) -1.5 (wbclp1) + 0.15 (wbclc2)- $\quad 0.2$ (reivab)- $\quad 0.5$ (reoxyg) +1.1 (surger)1.3(pnem1)- 0.6(pnem2) +2.6(dmant) + 0.7(dmasa) . 
Table 1: Result of Univariate Analysis, Showing limproved Percentage, Relative Risk with 95\% Confidence Interval and P-Value of Statistically Significant Variables

\begin{tabular}{|c|c|c|c|c|}
\hline Variables of Interest & Count & Improved \% & RR(95\% C.I.) & p-value \\
\hline \multicolumn{5}{|c|}{ Risk Factors } \\
\hline Present & 55 & 72.7 & $1.3(1.04,1.47)$ & 0.01 \\
\hline Coagulopathy (not present) & 948 & 58.4 & 1 & \\
\hline \multicolumn{5}{|c|}{ Medication } \\
\hline Warfarin (No) & 974 & 57.7 & 1 & \\
\hline Yes & 11 & 27.3 & $0.5(0.15,1.02)$ & 0.04 \\
\hline Antihypertansive (No) & 339 & 49 & 1 & \\
\hline Yes & 202 & 65.3 & $1.2(1.04,1.3)$ & 0.009 \\
\hline Weakness (No) & 514 & 52.5 & 1 & \\
\hline Yes & 471 & 62.6 & $1.2(1.09,1.3)$ & 0.001 \\
\hline Faintness (No) & 774 & 61.6 & 1 & \\
\hline Yes & 211 & 41.7 & $0.6(0.5,0.8)$ & 0.0001 \\
\hline Numbness (No) & 965 & 56.9 & 1 & \\
\hline Yes & 20 & 80 & $1.4(1,1.6)$ & 0.03 \\
\hline Dizziness (No) & 873 & 55.7 & 1 & \\
\hline 90-140, Normal & 206 & 60.7 & & 0.006 \\
\hline <90, Mild hypo. & 15 & 26.7 & $0.4(0.2,0.9)$ & \\
\hline 141-160,Mild htn & 215 & 59.5 & $1.0(0.8,1.1)$ & \\
\hline 161-200,Mod.htn. & 379 & 59.9 & $1(0.8,1.1)$ & \\
\hline$>200$,Sev.htn. & 170 & 47.6 & $0.8(0.6,0.9)$ & \\
\hline \multicolumn{5}{|c|}{ Mental Status } \\
\hline Normal & 286 & 77.3 & & 0.0001 \\
\hline Sleepy & 230 & 67.4 & $0.9(0.7,1.0)$ & \\
\hline Confused & 78 & 67.9 & $0.9(0.7,1.0)$ & \\
\hline Poorly Responsive & 57 & 45.6 & $0.7(0.3,0.8)$ & \\
\hline Unresponsive & 204 & 37.3 & $0.5(0.3,0.7)$ & \\
\hline Coma & 102 & 14.7 & $0.3(0.1,0.3)$ & \\
\hline
\end{tabular}


(Table 1). Continued.

\begin{tabular}{|c|c|c|c|c|}
\hline Variables of Interest & Count & Improved \% & RR(95\% C.I.) & p-value \\
\hline \multicolumn{5}{|c|}{ CN Palsy } \\
\hline Troch Lear (No) & 976 & 57.7 & 1 & \\
\hline Yes & 9 & 22.2 & $0.4(0.1,1)$ & 0.031 \\
\hline Trigeminal (No) & 974 & 57.7 & 1 & \\
\hline Yes & 11 & 27.3 & $0.5(0.2,1.02)$ & 0.042 \\
\hline Abducent (No) & 958 & 57.9 & 1 & \\
\hline Yes & 27 & 37 & $0.6(0.2,0.97)$ & 0.031 \\
\hline Facial (No) & 515 & 53.4 & 1 & \\
\hline Yes & 470 & 61.7 & $1.2(1.04,1.3)$ & 0.008 \\
\hline \multicolumn{5}{|c|}{ Speech } \\
\hline Normal & 608 & 55.1 & 1 & 0.0001 \\
\hline Dysarthria & 194 & 74.2 & $1.3(1.2,1.5)$ & \\
\hline Global Aphasia & 111 & 37.8 & $0.7(0.5,0.9)$ & \\
\hline wernick'e Aphasia & 12 & 91.7 & $1.7(1.04,1.79)$ & \\
\hline Brocas & 60 & 55 & $1(0.8,1.23)$ & \\
\hline \multicolumn{5}{|c|}{ Motor } \\
\hline Normal (Yes) & 227 & 49.8 & 1 & 0.009 \\
\hline No & 758 & 59.6 & $1.2(1.05,1.34)$ & \\
\hline Rt.monopaeesis (No) & 975 & 57 & 1 & \\
\hline Yes & 10 & 90 & $1.6(0.9,1.7)$ & 0.022 \\
\hline Lt.hemiparesis (No) & 697 & 54.5 & 1 & \\
\hline Yes & 288 & 64.2 & $1.2(1.04,1.3)$ & 0.005 \\
\hline Rt.hemiplegia (No) & 890 & 58.4 & 1 & \\
\hline Yes & 95 & 47.4 & $0.8(0.6,0.99)$ & 0.039 \\
\hline Lt.hemiplegia (No) & 845 & 59.3 & 1 & \\
\hline Yes & 140 & 45.7 & $0.8(0.6,0.9)$ & 0.003 \\
\hline \multicolumn{5}{|c|}{ Sensory } \\
\hline Normal & 873 & 54.9 & & 0.0001 \\
\hline Hemihypoasthesia & 94 & 77.7 & $1.4(1.2,1.6)$ & \\
\hline Neglect & 18 & 72.2 & $1.3(0.9,1.6)$ & \\
\hline \multicolumn{5}{|c|}{ Location } \\
\hline Cerebellum (No) & 936 & 56.3 & 1 & \\
\hline Yes & 49 & 77.6 & $1.4(1.1,1.6)$ & 0.002 \\
\hline Temporal Lobe (No) & 923 & 58.2 & 1 & \\
\hline Yes & 62 & 45.2 & $0.8(0.5,1)$ & 0.046 \\
\hline \multicolumn{5}{|c|}{ Mass Effect } \\
\hline Midline Shift (No) & 766 & 64.8 & 1 & \\
\hline Yes & 219 & 31.5 & $0.6(0.4,0.6)$ & 0.0001 \\
\hline Intraventricular Blood (No) & 718 & 63.5 & 1 & \\
\hline Yes & 267 & 40.8 & $0.7(0.5,0.8)$ & 0.0001 \\
\hline Hydrocephalus (No) & 889 & 60.1 & 1 & \\
\hline Yes & 96 & 32.3 & $0.5(0.4,0.7)$ & 0.0001 \\
\hline Normal (Yes) & 566 & 70.7 & 1 & 0.0001 \\
\hline No & 419 & 39.4 & $0.6(0.5,0.7)$ & \\
\hline
\end{tabular}




\begin{tabular}{|c|c|c|c|c|}
\hline Variables of Interest & Count & Improved \% & RR(95\% C.I.) & p-value \\
\hline \multicolumn{5}{|c|}{ White Blood Cells } \\
\hline$<4 \times 10^{3} / \mathrm{cc}$, leukopenia) & 15 & 40 & $0.6(0.3,1.0)$ & \\
\hline$>10^{4} / \mathrm{cc}$, leukocytosis) & 540 & 52.4 & $0.8(0.7,0.9)$ & \\
\hline \multicolumn{5}{|c|}{ Lowest SBP } \\
\hline $90-140$, Normal & 566 & 65.5 & & 0.0001 \\
\hline$<90$, Mild hypo. & 106 & 18.9 & $0.2(0.2,0.4)$ & \\
\hline 141-160,Mild htn & 140 & 66.4 & $1(0.9,1.1)$ & \\
\hline 161-200,Mod.htn. & 65 & 43.1 & $0.7(0.4,0.9)$ & \\
\hline $60-90$, Normal & 544 & 65.1 & & 0.0001 \\
\hline$<60$, Нypo. & 203 & 40.9 & $0.7(0.6,0.7)$ & \\
\hline 91-110,Mild htn & 117 & 60.7 & $0.9(0.8,1.1)$ & \\
\hline 111-120,Mod.htn. & 17 & 41.2 & $0.6(0.2,1.0)$ & \\
\hline$>120$, Sev.htn. & 7 & 14.3 & $0.2(0.03,0.9)$ & \\
\hline \multicolumn{5}{|c|}{ Received } \\
\hline IVABX (No) & 789 & 61.3 & 1 & \\
\hline Yes & 196 & 41.3 & $0.7(0.5,0.8)$ & 0.0001 \\
\hline$N G(\mathrm{No})$ & 720 & 61.7 & 1 & \\
\hline \multicolumn{5}{|c|}{ Complication } \\
\hline Pneumonia (not present) & 229 & 72.5 & 1 & \\
\hline Present & 154 & 31.2 & $0.5(0.3,0.6)$ & 0.0001 \\
\hline Don't know & 602 & 58.3 & $0.8(0.7,0.9)$ & \\
\hline MI (not present) & 315 & 62.2 & 1 & \\
\hline Present & 12 & 33.3 & $0.5(0.2,1.0)$ & 0.033 \\
\hline Don't know & 658 & 55.5 & $1.9(0.8,1.0)$ & \\
\hline Gastro I. bleed (not present) & 319 & 61.8 & 1 & \\
\hline Present & 10 & 30 & $0.5(0.2,1.0)$ & 0.041 \\
\hline Don't know & 656 & 55.6 & $0.9(0.8,1.0)$ & \\
\hline \multicolumn{5}{|c|}{ Discharge Medicine } \\
\hline Antihypertensive (No) & 437 & 28.1 & 1 & \\
\hline Yes & 548 & 80.7 & $2.9(2.7,3.0)$ & 0.0001 \\
\hline ASA (No) & 937 & 56 & 1 & \\
\hline Yes & 48 & 83.3 & $1.5(1.2,1.6)$ & 0.0001 \\
\hline Antilipidemics (No) & 916 & 55.7 & 1 & \\
\hline Yes & 69 & 79.7 & $1.4(1.2,1.6)$ & 0.0001 \\
\hline
\end{tabular}


(Table 1). Continued.

\begin{tabular}{|c|c|c|c|c|}
\hline Variables of Interest & Count & Improved \% & RR(95\% C.I.) & p-value \\
\hline \multicolumn{5}{|c|}{ Disposition } \\
\hline Home & 674 & 82.3 & & 0.0001 \\
\hline Hospital & 26 & 7.7 & & \\
\hline Died & 259 & 0 & & \\
\hline Length of Stay (days) & \multicolumn{2}{|c|}{ Mean ( S.E.) } & & \\
\hline Not Improved & \multicolumn{2}{|c|}{$5.38(0.36)$} & & \\
\hline Improved & \multicolumn{2}{|c|}{$8.22(0.29)$} & $1.03(1.01,1.1)$ & $<0.0001$ \\
\hline
\end{tabular}

Table 2: Biologically Meaningful Interaction Terms

\begin{tabular}{|c|c|c|c|c|}
\hline Variable's Combination & -2 log likelihood & G - Statistics & Degree of freedom & p-value \\
\hline age $\times$ htn & 632.325 & 0.066 & 1 & $>0.05$ \\
\hline age $x$ mahtn & 629.526 & 2.925 & 1 & $>0.05$ \\
\hline age $\times$ Isbp & 625.036 & 7.415 & 4 & $>0.05$ \\
\hline age $\times$ dmant & 632.445 & 0.006 & 1 & $>0.05$ \\
\hline htn $x$ mahtn & 629.117 & 3.334 & 1 & $>0.05$ \\
\hline htn $\times$ Isbp & 626.382 & 6.069 & 3 & $>0.05$ \\
\hline htn $x$ dmant & 630.836 & 1.615 & 1 & $>0.05$ \\
\hline memidsh $\mathrm{x}$ surger & 631.483 & 0.968 & 1 & $>0.05$ \\
\hline mehydr $x$ surger & 632.439 & 0.012 & 1 & $>0.05$ \\
\hline reoxyg x pnem & 632.394 & 0.057 & 2 & $>0.05$ \\
\hline
\end{tabular}

-2 log likelihood of main effect model $=\lambda=632.451$.

The discrimination of the prediction model was determined by measuring the accuracy, sensitivity, specificity and area under the receiver operating characteristic (ROC) curve (Table 4).

\section{DISCUSSION}

The inference of data through univariate analysis revealed that out of 88 covariates 46 were found to be significant (Table 1) according to $p$-value $<0.05$.

Statistical analysis showed that $84.8 \%$ subjects were found to have hypertension as major risk factor. The inference of data through univariate analysis, revealed that hypertensive subjects showed apparent improvement (1.12 times) as compared to non hypertensive patients (95\% C.I.: 0.95 - 1.27) for outcome variable. Contrary to this the multivariable analysis using multiple logistic regressions, interestingly exhibited a significant negative relationship between $\mathrm{ICH}$ and hypertension; when these data were adjusted for other variables in the statistical model. The improvement among ICH patients having hypertension was $0.5(p=0.001, A R R=0.5,95 \%$ C.I. $0.3-0.8$ ) as compared to non hypertensive's when adjusted for other variables in the model.

Results of present study as reported in multivariable analysis were in accordance to the results of a previous study [18]. Other studies [2, 14, 19-25] showed a clear relationship between hypertension and $\mathrm{ICH}$. The results of present study intensely support the scientific concept of direct relation of hypertension with $\mathrm{ICH}$.

Recent data showed that $65.6 \%$ subjects were using antihypertensive medicine. Multivariable analysis exhibited a significant relationship between $\mathrm{ICH}$ and antihypertensive medicine when these data were adjusted for other variables in given best fitted model (Table 3). The improvement among ICH patients using antihypertensive medicine was $1.3(\mathrm{p}=0.031$, $\mathrm{ARR}=1.3,95 \%$ C.I. $1.1-1.5$ ) as compared to those who were not using antihypertensive medicine when adjusted for other variables in the model. Thrift et al. (1998) [22], reported that the use of antihypertensive 
Table 3: Multiple Logistic Regression Estimates of Covariates of given Model, Showing Relative Risk and Adjusted Relative Risk with $95 \%$ Confidence Interval and p-Value for the Outcome Variable of ICH

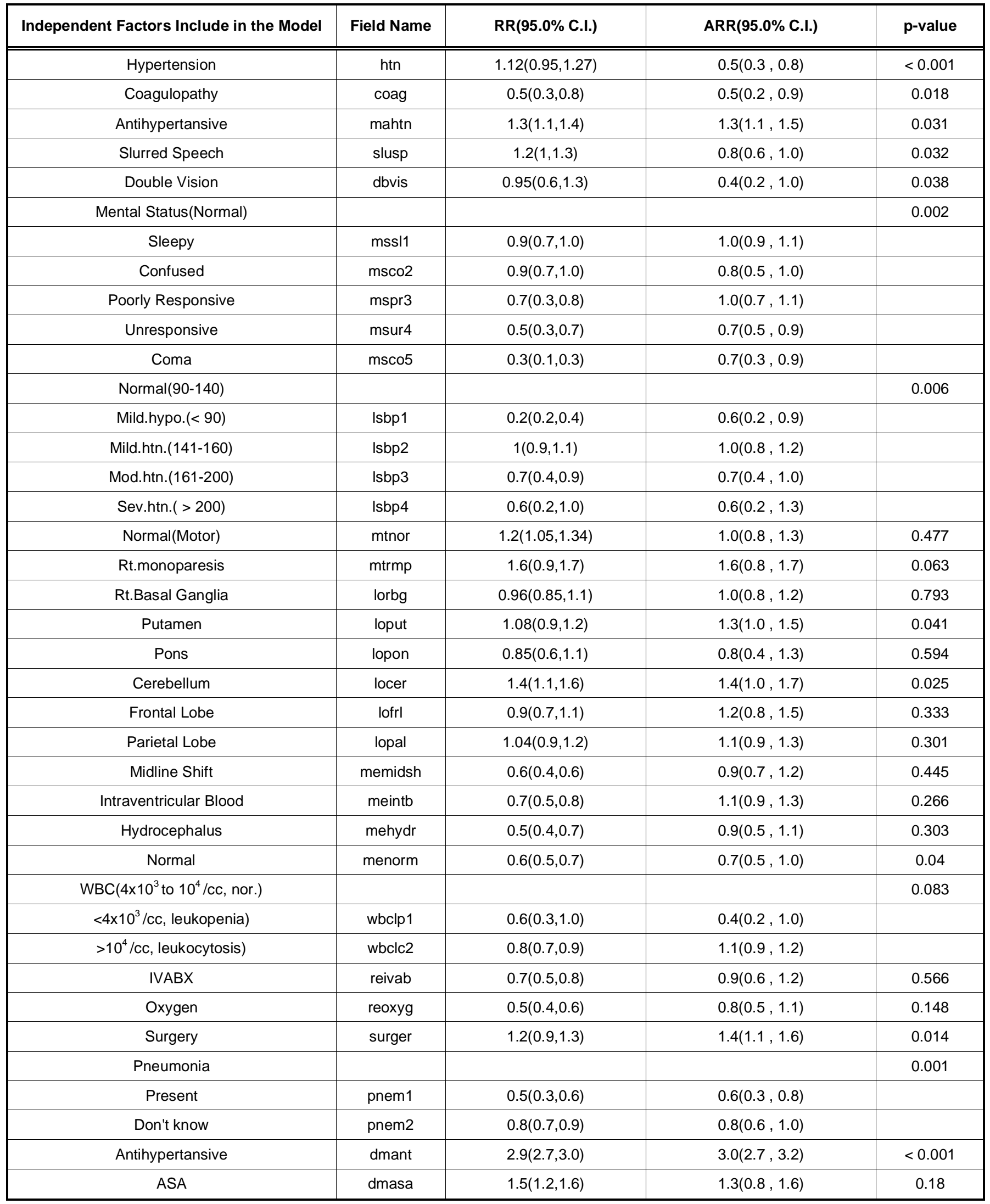


Table 4: Sensitivity and Specificity Analysis with 95\% C.I. of Good Fitted Multiple Logistic Regression Model

\begin{tabular}{|c|c|}
\hline Cutoff Value & 0.521 \\
\hline Area under ROC curves (95\% C.I.) & $0.892(0.869,0.915)$ \\
\hline Sensitivity (95\% C.I.) & $0.852(0.816,0.883)$ \\
\hline Specificity (95\% C.I) & $0.793(0.746,0.834)$ \\
\hline Positive Predictive Value (95\% C.I.) & $0.849(0.812,0.879)$ \\
\hline Negative Predictive Value (95\% C.I.) & $0.798(0.750,0.838)$ \\
\hline
\end{tabular}

\section{ROC Curve}

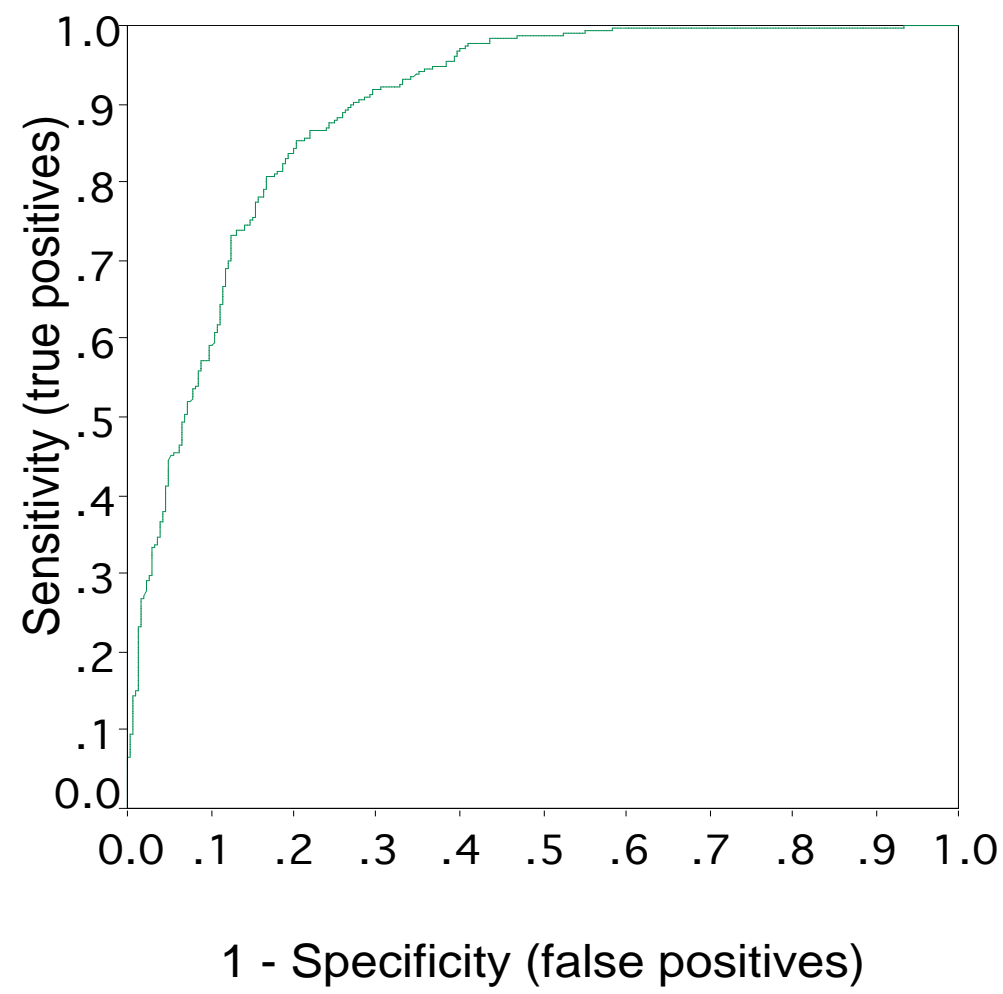

medicine decrease the risk of $\mathrm{ICH}$ due to hypertension. Thus results of present study showed that $\mathrm{ICH}$ has strong relationship with use of antihypertensive medicine and it can be hypothesized that the use of antihypertensive medicine decreases the risk of occurrence of $\mathrm{ICH}$ due to hypertension. The result of this study clearly presented that $84.8 \% \mathrm{ICH}$ patients have a risk factor of hypertension, $65.6 \% \mathrm{ICH}$ patients take antihypertensive medicine while $31.9 \%$ do not take any medicine. So we can conclude that improvement in $\mathrm{ICH}$ patients, who develop hypertension was 0.5 times ( $A R R=0.5$ ) as compared to those who did not develop hypertension. In the same way at the time of discharge, $56 \%$ subjects were using antihypertensive medicine. Multivariable analysis showed that there is a relationship between $\mathrm{ICH}$ and antihypertensive medicine. The improvement among
$\mathrm{ICH}$ patients who were using antihypertensive medicine at the time of discharge as resulted from multiple logistic regression model was 3.0 times $(p<0.001$, $\mathrm{ARR}=3.0,95 \%$ C.I. $2.7-3.2$ ) as compared to those who did not use antihypertensive medicine. Thus the change in adjusted relative risk (ARR) from 1.3 to 3.0 times in antihypertensive medicine shows that the use of antihypertensive medicine and $\mathrm{ICH}$ outcome variable are positively associated.

Since hypertension is a significant risk factor, the different group of level or range of blood pressure plays an important role in improvement of subjects. Before discussion of different groups of range of blood pressure, it is important to inform that there are four groups of range of blood pressure in the present study. Two, at the time of admission after ICH, i.e., initial SBP 
and DBP and two, during the period of admission in hospital, i.e., lowest SBP and DBP.

In the analysis of present data for different range of blood pressure, it was revealed that, in initial systolic blood pressure a large number of patients (78\%) belongs to the hypertensive blood pressure group of range $(141-200 \mathrm{~mm} \mathrm{Hg})$ and $21 \%$ patients have normal blood pressure group of range $(90-140 \mathrm{~mm} \mathrm{Hg})$. Similarly in initial diastolic blood pressure group, $56 \%$ belong to the hypertensive blood pressure group of range (>90 $\mathrm{mm} \mathrm{Hg}$ ) and $40.9 \%$ patients have normal diastolic blood pressure group of range $(60-90 \mathrm{~mm} \mathrm{Hg})$. In the same way during the hospitalization of patients with SBP it was found that $25 \%$ belong to the hypertensive blood pressure group of range(141-200 $\mathrm{mm} \mathrm{Hg}$ ) and $64 \%$ patients have normal blood pressure group of range $(90-140 \mathrm{~mm} \mathrm{Hg})$. Similarly with reference to diastolic blood pressure during the hospitalization, $10 \%$ of patients belong to the hypertensive blood pressure group of range $(>90 \mathrm{~mm}$ $\mathrm{Hg}$ ) and $62 \%$ patients have normal diastolic blood pressure group of range $(60-90 \mathrm{~mm} \mathrm{Hg})$.

The improvement among $\mathrm{ICH}$ patients who belong to hypertensive lowest systolic blood pressure group $(141-160 \mathrm{~mm} \mathrm{Hg})$ was 1.02 times $(\mathrm{p}=0.006$, $\mathrm{ARR}=1.02,95 \%$ C.I. $0.8-1.2)$, for the range of $(161-$ $200 \mathrm{~mm} \mathrm{Hg}$ ) was 0.7 times ( $p=0.006, A R R=0.7,95 \%$ C.I. $0.4-0.9)$ and for the range of ( $>200 \mathrm{~mm} \mathrm{Hg}$ ) was 0.6 times $(p=0.006, A R R=0.6,95 \%$ C.I. $0.2-1.3)$ as compared to the normal range $(90-140 \mathrm{~mm} \mathrm{Hg})$ of blood pressure when adjusted for other variables in the best fitted model. Thus the change in adjusted relative risk (ARR) of hypertensive range of systolic blood pressure also indicates that the blood pressure range and $\mathrm{ICH}$ outcome variable are negatively associated.

Results of current data analysis as reported in multivariable case are in accordance to the results of previous studies. Leppala et al. (1999) [26] showed that the risk of $\mathrm{ICH}$ is increased with increasing systolic and diastolic blood pressure. Song et al. (2004) [27] supported the closer relationship between hemorrhagic stroke and blood pressure level. Kin et al. (2005) [24] indicated the risk ratio of blood pressure level and hemorrhage was associated. Hence it can be concluded that the risk of $\mathrm{ICH}$ is increased with increasing systolic blood pressure, as already hypothesized above in discussion of hypertension that $\mathrm{ICH}$ has strong relationship with hypertension.

The second and third highest frequencies of risk factor noted in this study were diabetes mellitus
(24.3\%) and hyperlipidemia (13.4\%). As far as these two major risk factors are concerned; results are quit interesting. Work done by researchers [18, 28-31] showed that diabetes mellitus is not an independent risk factor for the development of $\mathrm{ICH}$. However it increases mortality rate in subjects with $\mathrm{ICH}$ since hyperglycemia is reported to increase edema and infarct size and with reduction in cerebral blood flow and cerebrovascular reserves. These indicate an indirect correlation of DM and hyperlipidemia with $\mathrm{ICH}$. Sturgeon et al. 2007 [25] also showed that diabetes mellitus is not associated ( $p>0.05$ ) with $\mathrm{ICH}$ either in univariate and multivariate models. Arboix et al. (2000) [29] showed that diabetes mellitus increases the mortality rate in subjects with $\mathrm{ICH}$. The univariate and multivarible analysis of present data showed insignificant relationship between $\mathrm{ICH}$ and these risk factors. Diabetes mellitus subjects with $\mathrm{ICH}$ outcome variable indicated less improvement (0.9 times) with non significant relationship $(p<0.17)$ as compared to non-diabetic subjects. Diabetes mellitus and hyperlipidemia were not selected in the model as a candidate of best fitted model, when adjusted for other variables in the model.

The assessment of coagulopathy expected that 3.7 $\%$ subjects had this risk factor. The univariate analysis showed less clinical improvement (0.5 times) in coagulopathy subjects with $\mathrm{ICH}$, as compared to non coagulopathic subjects (95\% C.I.: $0.3-0.8)$ for outcome variable. Multivarible analysis showed a negative significant relationship between $\mathrm{ICH}$ and coagulopathy when adjusted for other variables in the best fitted model. The improvement among $\mathrm{ICH}$ patients with coagulopathy was 0.5 times $(p=0.018$, $\mathrm{ARR}=0.5,95 \%$ C.I. $0.2-0.9$ ) as compared to without coagulopathy when adjusted for other variables in the model.

Present Model has 0.892 area under the curve with sensitivity (0.852), specificity (0.793) and p-value (0.204). This indicates that the model give the impression to fit quite well for predictive performance of the $\mathrm{ICH}$ outcome variable. The value of the area under the curve, sensitivity and specificity showed that the model is applicable.

\section{CONCLUSION}

The present statistical model of multiple logistic regression suggested that $\mathrm{ICH}$ has strong relationship with hypertension and the use of antihypertensive medicine was found to play a pivotal role in reduction of 
the risk of $\mathrm{ICH}$ due to hypertension. They showed a clear improvement (1.3 times) in $\mathrm{ICH}$ patients as compared to those not using antihypertensive medicine. Likewise, statistical analysis showed a clear improvement (3.0 times) among ICH patients who were using antihypertensive medicine at the time of discharge. Thus the change in adjusted relative risk from 1.3 to 3.0 times illustrate that the use of antihypertensive medicine and $\mathrm{ICH}$ outcome variable are positively associated. Similarly, the change in adjusted relative risk of different range of level of blood pressure showed that the blood pressure level and $\mathrm{ICH}$ outcome are significantly associated. Therefore, it can be tested that the risk of $\mathrm{ICH}$ is increased with increase in blood pressure. From other risk factors, coagulopathy was found as a negatively significant risk factor for $\mathrm{ICH}$ outcome in the fitted model.

Multiple logistic regressions revealed that neurological symptomatology, slurred speech and double vision are important factors of proposed statistical models. Moreover, multivariable analysis discovered a clear decrease in mental status from normal to coma in applicable model. Putamen and cerebellum were positively significant with $\mathrm{ICH}$ outcome.

Multivariable analysis pointed out insignificant relationship between white blood cells and $\mathrm{ICH}$; however WBC was selected as a candidate in the multiple logistic regression model. Hence white blood cells are essential for the best fitted model. Current statistical evaluation found that the surgery is an important part of recovery of $\mathrm{ICH}$ patients and estimated that the improvement among the $\mathrm{ICH}$ patients, who were treated with surgery, was 1.4 times with significant $p$-value in best multiple logistic regression models. Multivariable analysis showed that the complication of pneumonia during treatment of $\mathrm{ICH}$ subjects has highly significant negative association with outcome variable.

The above findings also intended that the multivariable analysis using multiple logistic regressions and statistical diagnostic tools are better techniques of binary response variable because multiple logistic regressions provides an easy interpretation and identify the most important factors from the multiple factor diseased data.

\section{REFERENCES}

[1] Wasay M Khatri IA, Khealani B, Afaq M. Temporal Trends in Risk Factors and Outcome of Intracerebral Hemorrhage Over
18 Years at a Tertiary Care Hospital in Karachi, Pakistan. J Stroke Cerebrovasc Dis 2010; 21(4): 289-92.

http://dx.doi.org/10.1016/j.jstrokecerebrovasdis.2010.09.001

[2] Woo D, Haverbusch M, Sekar P, et al. Effect of Untreated Hypertension on Hemorrhagic Stroke. Stroke 2004.

http://dx.doi.org/10.1161/01.STR.0000130855.70683.c8

[3] Park JK, Kim HJ, Chang SJ, Koh SB, Koh SY. Risk Factors for Hemorrhagic Stroke in Wonju, Korea. Yonsei Med J 1998; 39(3): 229-35.

[4] Qureshi AI, Tuhrim S, Broderick JP, Batjer HH, Hondo H, Hanley DF. Spontaneous Intra cerebral Hemorrhage: Review Article. New Engl J Med 2001; 344(19): 1450-59. http://dx.doi.org/10.1056/NEJM200105103441907

[5] Fewel MF, Thompson BG, Hoff JT. Spontameous Intra circular hemorrhage: a review. Neursurg Focus 2003; 15(4): 1-16.

[6] Takahashi O, Cook EF, Nakamura T, Saito J, Ikawa F, Fukui T. Risk Stratification for In-hospital Mortality in Spontaneous Intracerebral Haemorrhage: A Classification and Regression Tree Analysis. Q J Med 2006; 99: 743-50.

http://dx.doi.org/10.1093/qjmed/hcl107

[7] Nassisi D. Stroke, Hemorrhagic 2005.

[8] Hosmer DW, Lemeshow S. A Goodness-of-fit test for the Multiple Logistic Regression Model. Commun Statist 1980; 9(10): 1043-69. http://dx.doi.org/10.1080/03610928008827941

[9] Lemeshow S, Hosmer DW. The use of Goodness of fit Statistics in the Development of Logistic Regression Model. Am J Epidemiol 1982; 115(1): 92-166.

[10] Hosmer DW, Lemeshow S. Applied Logistic Regencies. A Wiley-Interscience Publication 1989, 2000.

[11] Cessie LS, Houwelingen JCV. A Goodness-of-Fit Test for Binary Regression Models, Based on Smoothing Methods. Biometrics 1991; 47(4): 1267-82.

http://dx.doi.org/10.2307/2532385

[12] Hosmer DW, Hosmer T, Cessie SL, Lemeshow S. A Compairision of Goodness-of-fit tests for the Logistic Regression Model. Statist Med 1997; 16: 965-80.

http://dx.doi.org/10.1002/(SICl)10970258(19970515)16:9<965::AID-SIM509>3.0.CO;2-O

[13] Collett D. Modeling Binary data, $2^{\text {nd }}$ ed. Chapman and Hall 2003.

[14] Chuang YC, Chen YM, Peng SK, Peng SY. Risk Stratification for Redacting 30-day mortality of Intracerebral Hemorrhage. Int J Quality Health Care 2009; 21(6): 441-47. http://dx.doi.org/10.1093/intghc/mzp041

[15] Bendel RB, Afifi AA. Comparison of Stopping Roles in Forward "Stepwise" Regression. J Am Statist Assoc 1977; 72(357): 46-53.

[16] Sauerbrei W. The use of Resampling Methods to Simplify Regression Models in Medical Statistics. Appl Statist 1999; 48(3): 313-29.

http://dx.doi.org/10.1111/1467-9876.00155

[17] Caberlotto L, Hurd YL. Neuropeptide Y Y1 and Y2 Receptor mRNA Expression in the Prefrontal Cortex of Psychiatric Subjects Relationship of Y2 Subtype to Suicidal Behavior. Neuropsychopharmacology 2001; 25: 91-97. http://dx.doi.org/10.1016/S0893-133X(00)00231-1

[18] Ariesen MJ, Claus SP, Rinkel GJE, Algra A. Risk Factors for Intracerebral Hemorrhage in the General Population: A Systematic Review, American Heart Association. Stroke 2003; 34: 2060-65. http://dx.doi.org/10.1161/01.STR.0000080678.09344.8D

[19] Brott T, Thalinger K, Hertzberg V. Hypertension as a Risk Factor for Spontaneous Intracerebral Hemorrhage, American Heart Association. Stroke 1986; 17(6): 1078-83.

http://dx.doi.org/10.1161/01.STR.17.6.1078 
[20] Juvela S, Hillbom M, Palomäki H. Risk Factors for Spontaneous Intracerebral Hemorrhage. Stroke 1995; 26: 1558-64. http://dx.doi.org/10.1161/01.STR.26.9.1558

[21] Dandapani BK, Suzuki S, Kelley RE, Iglesias YR, Duncan RC. Relation Between Blood Pressure and Outcome in Intracerebral Hemorrhage, American Heart Association. Stroke 1995; 26: 21-24. http://dx.doi.org/10.1161/01.STR.26.1.21

[22] Thrift AG, McNeil JJ, Forbes A, Donnan GL. Three Important Subgroups of Hypertensive Persons at Greater Risk of Intracerebral Hemorrhage, American Heart Association. Hypertension 1998; 31: 1223-29. http://dx.doi.org/10.1161/01.HYP.31.6.1223

[23] Broderick JP, Adams HP, Barsan W, et al. Guidelines for the Management of Spontaneous Intracerebral Hemorrhage: A Statement for Healthcare Professionals From a Special Writing Group of the Stroke Council, American Heart Association. Stroke 1999; 30: 905-15. http://dx.doi.org/10.1161/01.STR.30.4.905

[24] Kim HC, Nam CM, Jee SH, Suh I. Comparison of Blood Pressure Associated Risk of Intracerebral Hemorrhage and Subarachnoid hemorrhage: American Heart Association. Hypertension 2005; 46: 393-97. http://dx.doi.org/10.1161/01.HYP.0000177118.46049.e6

[25] Sturgeon JD, Folsom AR, Longstreth WT, Shahar E, Rosamond WD, Cushman M. Risk Factors for Intracerebral Hemorrhage in a Pooled Prospective Study. Stroke 2007; 38: 2718-25.

http://dx.doi.org/10.1161/STROKEAHA.107.487090
[26] Leppälä JM, Virtamo J, Fogelholm R, Albanes D, Heinonen OP. Different Risk Factors for Different Stroke Subtypes: Association of Blood Pressure, Cholesterol, and Antioxidants, American Heart Association. Stroke 1999; 30: 2535-40. http://dx.doi.org/10.1161/01.STR.30.12.2535

[27] Song YM, Sung J, Lawlor DA, Smith GD, Shin Y, Ebrahim S. Blood Pressure, Haemorrhagic Stroke and Ischaemic Stroke: The Korean National Prospective Occupational Cohort Study. BMJ 2004; 328: 324-25. http://dx.doi.org/10.1136/bmj.328.7435.324

[28] Wong KS. Risk Factors for Early Death in Acute Ischemic Stroke and Intracerebral Hemorrhage: A Prospective Hospital-Based Study in Asia, American Heart Association. Stroke 1999; 30: 2326-30. http://dx.doi.org/10.1161/01.STR.30.11.2326

[29] Arboix A, Massons J, García-Eroles L, Oliveres M, Targa C. Diabetes is an Independent Risk Factor for In-Hospital Mortality from Acute Spontaneous Intracerebral Hemorrhage. Diabetes Care 2000; 23: 1527-32. http://dx.doi.org/10.2337/diacare.23.10.1527

[30] Passero S, Ciacci G, Ulivelli M. The Influence of Diabetes and Hyperglyce-mia on Clinical Course after Intracerebral Hemorrhage. Stroke 2003.

[31] Rosand J, Eckman MH, Knudsen KA, Singer DE, Greenberg $S$. The Effect of Warfarin and Intensity of Anticoagulation on Outcome of Intrac-erebral Hemorrhage. Arch Intern Med 2004; 164: 880-84. http://dx.doi.org/10.1001/archinte.164.8.880

Received on 24-08-2012

http://dx.doi.org/10.6000/1929-6029.2013.02.01.03

(C) 2013 Siddiqui et al.; Licensee Lifescience Global.

This is an open access article licensed under the terms of the Creative Commons Attribution Non-Commercial License (http://creativecommons.org/licenses/by-nc/3.0/) which permits unrestricted, non-commercial use, distribution and reproduction in any medium, provided the work is properly cited. 